ANUARIo De Estudios Medievales

51/1, enero-junio de 2021 , pp. $3-28$

ISSN 0066-5061

https://doi.org/10.3989/aem.2021.51.1.01

\title{
INTRODUCCIÓN. LOS PRELADOS BAJOMEDIEVALES IBÉRICOS Y SU PATRONAZGO ARTÍSTICO EN CONTEXTO
}

\author{
INTRODUCTION. LATE MEDIEVAL IBERIAN PRELATES \\ AND THEIR ARTISTIC PATRONAGE IN CONTEXT
}

Aunque presentes desde principios del siglo XX, los estudios de patronazgo artístico vienen desarrollándose con fuerza creciente desde su segunda mitad, favorecidos por la relevancia del análisis interdisciplinar, que permite situar en su contexto el hecho artístico ${ }^{1}$. La variada y compleja realidad del patrocinio artístico medieval ha derivado en una fragmentación de la que han ido surgiendo diversas categorías por cronología, situación social, especificidad profesional o género. Evidentemente, los patronos pertenecientes a las élites han seguido acaparando la atención de los investigadores, en cuanto generaron una producción artística diversa, cuantiosa, novedosa y de gran calidad. Entre ellos, los obispos y arzobispos han ocupado en los últimos años un puesto relevante, favorecido por el interés de los medievalistas por conocer su papel en la sociedad de su momento ${ }^{2}$, en sus facetas de político, diplomático, intelectual, reformador religioso, militar, administrador económico e institucional, además de la imprescindible aportación de los estudios prosopográficos.

Este volumen monográfico, que se presenta bajo el título Arte y poder episcopal en la Península Ibérica durante la Baja Edad Media, pretende mostrar la vitalidad de los estudios sobre patronazgo artístico episcopal en el ámbito ibérico, a partir de las aportaciones de algunos de los más significativos medievalistas de la actualidad, que han dedicado una buena parte de su tarea investigadora a estos relevantes personajes, tanto desde el ámbito histórico -Óscar Villarroel, Santiago Domínguez, Josep Antoni Iglesias-Fonseca, que aportan el imprescindible contexto de desarrollo de la producción artística objeto de estudio-, como, especialmente, desde la historia del arte -Begoña Alonso, Nicolas Bock, Gerardo Boto y Marta Serrano, Clara Fernández-Ladreda, Juan Carlos Ruiz Souza, José Alberto Moráis, Marta Cendón y David

\footnotetext{
${ }^{1}$ Entre otros, Yarza 1992; Caskey 2006; Quintavalle 2011; Alcoy, et al. 2012; Hourihane 2013.

${ }^{2}$ Guenée 1987; Merlo 2003; Aurell, García de la Borbolla 2004; Guijarro 2019.

Citation / Cómo citar este texto: Teijeira Pablos, M. ${ }^{a}$ Dolores; Herráez Ortega, M. ${ }^{a}$ Vitoria (2021), Introducción Los prelados bajomedievales y su patronazgo artístico en contexto, "Anuario de Estudios Medievales" 51/1, pp. 29-72. https://doi.org/10.3989/aem.2021.51.1.01

Copyright: (C) 2021 CSIC. Este es un texto de acceso abierto distribuido bajo los términos de la licencia de uso y distribución Creative Commons Reconocimiento 4.0 Internacional (CC BY 4.0).
} 
Chao y María Concepción Cosmen-, que además de analizar algunos casos concretos muestran los intereses específicos de estos prelados. El marco cronológico de este volumen es la Baja Edad Media (siglos XIII-XV), periodo que coincide con la consolidación del poder episcopal tras la reforma gregoriana, el establecimiento de estrechas relaciones con la monarquía y el inicio de los grandes proyectos catedralicios, en los que ambas instituciones tuvieron un papel fundamental. El marco geográfico es el hispánico, con aportaciones focalizadas en las coronas de Aragón, Castilla y Navarra y las relaciones y transferencias artísticas entre ellas, incluyendo los territorios extrapeninsulares en los que tuvieron influencia, como sucede en el caso de la corona aragonesa y su expansión por el Mediterráneo, que estudia el Dr. Bock centrándose en la ciudad de Nápoles y las aportaciones artísticas de sus obispos.

La propuesta parte del grupo de investigación "Patrimonio Artístico Medieval" de la Universidad de León (GIR ULE 435), dentro del marco del proyecto de investigación que actualmente desarrolla, "El patronazgo artístico en el reino de Castilla y León (1230-1500). Obispos y catedrales II"3, que continua una trayectoria previa ya larga en proyectos de investigación sobre el tema, con resultados que consideramos relevantes, como los recientes volúmenes de estudios Reyes y Prelados. La creación artística en los reinos de León y Castilla (1050-1500) y Obispos y catedrales. Arte en la Castilla bajomedieval ${ }^{4}$.

\section{OBISPOS Y REDES DE PODER. UNA VÍA DE RENOVACIÓN DEL ARTE GÓTICO}

Los prelados han interesado tradicionalmente como figuras de poder en cuanto que son representantes fundamentales de la institución eclesiástica. Herederos de los apóstoles en la construcción y consolidación de la Iglesia, a partir de la reforma gregoriana se determinan claramente sus poderes, que operaban en el orden (sacramental y litúrgico), el magisterio (la predicación y la formación) y la jurisdicción (la administración económica y de la justicia eclesial, así como el gobierno de la curia y casa episcopal) $)^{5}$.

Desde el punto de vista artístico los investigadores se han interesado especialmente por las consecuencias del primero y el tercero de estos ámbitos competenciales, sin dejar de lado la labor docente, que podía traducirse

\footnotetext{
${ }^{3}$ HAR2017-88045, financiado por el Ministerio de Ciencia, Innovación y Universidades y Fondos Feder.

${ }^{4}$ Teijeira, Herráez, Cosmen 2014; Herráez, et al. 2018. Otras publicaciones del grupo en http://pam-ule.es/.

${ }^{5}$ Díaz 1998.
} 
en el fomento del sermón -fuente iconográfica de la máxima trascendencia y generador de espacios y de mobiliario litúrgico específico- y en la creación y dotación de colegios de diverso tipo -incluidos los universitarios- y de otros espacios de índole cultural, como las bibliotecas.

En el ejercicio del orden se ha tenido en cuenta la capacidad del obispo en la disposición, vigilancia y presidencia de la liturgia, sobre todo por lo que respecta a la consagración de nuevos templos, pero también al correcto funcionamiento de los ya existentes.

En el ejercicio jurisdiccional destaca su capacidad legislativa, judicial y ejecutiva, así como la administrativa, que incluía su obligación de gestionar y mantener el a menudo cuantioso patrimonio de la mesa episcopal; competencia suya era, pues, la correcta dotación, conservación y uso de los bienes eclesiásticos. Además, la celebración de sínodos y concilios, de los que surgían estatutos y constituciones, y las visitas determinaban normas que podían tener su influencia en la producción artística ${ }^{6}$.

Por otra parte, como príncipes de la Iglesia, los prelados desarrollaron un evidente interés en la promoción de su figura y el reforzamiento de un poder basado en la autoridad de la institución a la que representaban, el prestigio de sus antecesores y de su sede y su cercanía e influencia en otros poderes como el monárquico, pero también en su relación con el papado, lo que les permitió tejer intrincadas redes, de las que algunos ejemplos se estudian en el primer bloque de este volumen. Muchos estudios recientes recogen los mecanismos, incluidos los artísticos, utilizados por los prelados para conseguir estos objetivos, así como los escenarios de esta acción episcopal, entre los que se encontraban la corte regia y la curia pontificia?.

El monarca medieval se valió de la Iglesia como fuente de legitimidad y de sus prelados como agentes, entre otras cosas en las embajadas que estudia en este volumen el Dr. Villarroel en su destino a la Curia papal, cuyas consecuencias artísticas, ejemplificadas en algunos prelados, que pudieron conocer a través de las embajadas las novedades artísticas que se estaban produciendo fuera de Castilla, nos presenta la Dra. Alonso. Por su parte, muchos de estos obispos aprovecharon la ayuda regia en su cursus honorum y se inspiraron en su corte para crear todo un sistema de símbolos y discursos visuales que reforzasen una imagen de poder basada en su carácter de señor territorial

\footnotetext{
${ }^{6}$ Las constituciones y estatutos que intentaron corregir y castigar errores, infracciones y conductas contrarias al derecho canónico y a la moral cristiana recogieron en ocasiones cuestiones como el tipo y características de las sepulturas en sagrado, el cuidado de los templos y sus ornamentos, la solemnidad y magnificencia de la liturgia, pero también la resolución de problemas teológicos que afectaron a los temas representados en las obras y a su uso.

${ }^{7}$ Joubert 2006; Danielson, Gatti 2014.
} 
y cabeza de su iglesia, a través, entre otros instrumentos, de las obras de arte que encargaron.

En la curia pontificia, de la que obispos y arzobispos dependían orgánicamente y en la que muchos tuvieron cargos importantes, tanto en Roma como en Aviñón, conocieron nuevas obras, artistas y formas y todo ello hubo de condicionarles necesariamente en el desarrollo de su patronazgo artístico en sus sedes hispanas, como hubo de hacerlo igualmente la conciencia de la relevancia de su cargo en contacto con el uso que de la imagen de la institución se hacía en el ámbito pontificio. En cualquier caso, este es un tema en el que aún debe indagarse más y que necesita la concurrencia de investigadores que conozcan bien este contexto, como es el caso del Dr. Domínguez, que plantea en este volumen el marco de las relaciones entre el papado y el clero hispano en una cuestión especialmente espinosa: la colación de beneficios.

Los prelados impulsaron el uso de una serie de dispositivos que operaban en el plano sensorial, emocional o intelectual de sus destinatarios, creando auténticas puestas en escena de fuerte impacto visual: la actividad litúrgica ordinaria y extraordinaria, la ritualización de las ceremonias institucionales, los bienes destinados a la perpetuación y repetición de la memoria ${ }^{8}$. Con ello crearon y potenciaron una imagen propia, siempre en relación con su estado, a la que fueron dando forma a lo largo de su vida y su carrera, pero que quisieron mantener también activa tras su muerte. Esta imagen se forjó de modos diferentes según los momentos, los lugares y las circunstancias particulares y en ella participó, de manera dinámica, la obra de arte, más allá de las tradicionales categorías, incluso más allá de su propia materialidad.

Estas obras de promoción episcopal se encuentran fundamentalmente en el escenario básico del obispo, la catedral como sede de la cathedra, por lo que la mayor parte de los estudios sobre el tema, antiguos y recientes, se han desarrollado en relación con los de estos edificios.

\subsection{El prelado en la catedral. El interés por la fábrica del templo mayor y su magnificencia}

La autonomía institucional de los cabildos, que en la península se produjo mayoritariamente en los inicios de la Baja Edad Media, otorgó a estos el papel director en la administración del patrimonio catedralicio y con él en la institución y en su edificio principal. De este modo, la construcción de las grandes catedrales góticas fue una tarea desarrollada fundamentalmente por los

\footnotetext{
${ }^{8}$ Boto, Escandell, Lozano 2019.
} 
capitulares, que asumieron la gestión de la "obra y fábrica", lo que suponía no solo la construcción del edificio, sino también su mantenimiento y la dotación del culto y la liturgia. Suministro de materiales, contratación de artistas, coordinación y gestión eficaz de las obras eran tareas que solían quedar en las manos del canónigo obrero o fabriquero, a quién ayudaban, para obras concretas, las comisiones nombradas por el cabildo entre sus miembros. Sin su labor diaria, continua y efectiva no hubiera sido posible levantar, y mantener, los edificios catedralicios y su actividad constante y así se ha venido poniendo de manifiesto en los estudios más recientes sobre las grandes catedrales del gótico?.

Ahora bien, no debe por ello minimizarse la acción del obispo. Bien es cierto que algunos se preocuparon poco o nada de las necesidades constructivas de sus templos, muchos de ellos porque no parecen haber tenido grandes intereses artísticos, otros por haberlos desviado hacia otras obras, otros ni siquiera llegaron a residir. Sin embargo, un número muy importante de ellos sí lo hizo y su actividad fue esencial para la construcción, reforma, actualización y magnificencia de su catedral. Además, sus iniciativas artísticas dieron como resultado, por lo general, obras más ambiciosas, vanguardistas y complejas, derivadas de su mejor formación, un mayor conocimiento de las novedades artísticas gracias a sus viajes o a su vida cortesana, su mayor disponibilidad de medios y una mayor libertad de actuación en la promoción de obras con una impronta más personal.

Aún no se ha llevado a cabo un estudio exhaustivo del papel de obispos y arzobispos en la realización de las grandes catedrales góticas hispanas, por lo que muchos han pasado desapercibidos como patronos. Sin embargo, los análisis más recientes señalan su participación en tareas fundamentales para los proyectos más ambiciosos, como el saneamiento, reorganización y control de las rentas propias de la institución catedralicia, incluida la creación de cofradías especiales como la de Dios, la Virgen y San Antolín que Gutierre Álvarez de Toledo (1426-1439) creó para la continuación de las obras en su catedral de Palencia ${ }^{10}$ o la de la Obra de Santa María de Toledo, fundada en 1345 por Gil de Albornoz (1338-1350) ${ }^{11}$; o la aplicación de multas. Además, obtuvieron fondos extraordinarios, como hicieron para la catedral ovetense sus obispos Rodrigo Sánchez de Arévalo (1457-1467) y Alonso de Palenzuela (1469-1485†), que recoge en su estudio la Dra. Alonso, gestionados bien ante el papa, para obtener la desviación de tercias o indulgencias a los que contribuyeran con sus limosnas, bien ante el rey para la aplicación de ciertos

\footnotetext{
9 Entre otros La Seu Vella 1991; Yarza, Herráez, Boto 2004; Martínez de Aguirre 2006; Payo 2008; Gonzálvez 2010.

${ }^{10}$ Herráez 2018, p. 246.

${ }^{11}$ Cros 2008, vol. I, pp. 67-68.
} 
tributos. Igualmente hicieron aportaciones de la mesa episcopal y de su propio peculio, además de sus legados testamentarios, como los de Alonso de Fonseca y Ulloa a sus catedrales de Ávila (1445-1454) y Sevilla (1454-1464 y $1469-1473 \dagger)^{12}$. El estudio de las finanzas catedralicias y su aplicación a la realización del edificio y de su contenido ha permitido conocer con más detalle los procesos constructivos de estas grandes obras, ajustando adscripciones cronológicas, como ha sucedido en el caso de León ${ }^{13}$.

El lento avance de las obras catedralicias determinó que la mayoría de estos prelados llegaran a ver muy poco de sus magnos proyectos, dejando al cabildo y a sus sucesores la tarea de continuarlos, a menudo con actualizaciones y modificaciones del proyecto inicial que podían suponer un resultado muy distinto del planteado ${ }^{14}$. Algunos capitalizaron, a través de su heráldica, obras que deben realmente poco a su iniciativa, por lo que debemos ser cautelosos a la hora de determinar el papel real de cada uno.

¿Impusieron los prelados su gusto artístico en las obras catedralicias que promocionaron? Las fuentes primarias son muy parcas en este tipo de detalles, pero leyendo entre líneas la respuesta parece ser positiva: los prelados solían estar en contacto con los centros artísticos más activos, conocían las nuevas obras y muchos se han relacionado con la llegada de artífices que revolucionaron el panorama artístico local y la imagen del propio edificio catedralicio, como sucede en el famoso caso de Alonso de Cartagena, obispo de Burgos (1435-1456 $†$ y Juan de Colonia ${ }^{15}$.

A medida que avanza la investigación van añadiéndose a un listado ya extenso nuevos ejemplos de prelados relevantes tras los grandes proyectos catedralicios de la Baja Edad Media hispana; se trata generalmente de figuras poliédricas, de fuerte personalidad, dinámicas y bien relacionadas, deseosas de ligar su nombre, y el de su sede, a un gran proyecto que proporcionase a esta una imagen solemne, majestuosa y actualizada. Algunos de ellos son analizados en la tercera parte de este volumen, como sucede, desde la sugerente perspectiva del Dr. Ruiz Souza, en el caso de Rodrigo Jiménez de Rada (1209$1247 \dagger)$, eficaz impulsor de la renovación de la catedral toledana, que precisaba no solo un edificio menos vetusto y más funcional que la antigua mezquita mayor, sino también una imagen correspondiente al primer templo de un reino

${ }^{12}$ Las cantidades legadas son significativas: a la catedral abulense 40.000 maravedís -la mitad para un aniversario por su alma y la otra para la fábrica y ornamentos- y a la sevillana 100.000-200.000 para fábrica y ornamentos y 80.000 para una memoria por su alma-; Vasallo 2018, pp. 135-136, n. 127.

${ }^{13}$ Valdés, et al. 1994; Herráez 2004.

${ }^{14}$ Por ejemplo, sobre el lento proceso de realización de la catedral gótica de Palencia, Herráez 2018.

${ }^{15}$ Menéndez 2009; Martín 2013. 
cristiano que asumió su pasado islámico en diferentes claves ${ }^{16}$. Este marco privilegiado sería aprovechado por otros primados como escenario de su propio poder, como sucedió con Pedro Tenorio (1377-1399†) ${ }^{17}$. El prelado aprovechó la realización del claustro ${ }^{18}$, imprescindible en un conjunto catedralicio, para crear en su entorno dos obras mucho más personales: su capilla funeraria y la librería, maximizando así los recursos y la infraestructura de la obra "necesaria" para desarrollar las otras dos que, no por obedecer a intereses personales dejaban de ser ornato y servicio de la catedral. Todas se timbraron con las armas del arzobispo, en testimonio de su patronazgo. Esta ocupación episcopal del espacio claustral, tradicionalmente vinculado a los capitulares, no solo con un objetivo memorial, sino también formativo, reivindicando funciones propias del ius episcopale, suponía una recuperación de la imagen del prelado que, en esta catedral, se había visto desdibujada por la fuerte impronta regia.

No solo el templo y sus anexos religiosos constituyeron el marco de actuación de los prelados, las oficinas catedralicias fueron espacios de importante proyección episcopal: la sala capitular, el refectorio y el dormitorio (en el caso de cabildos no secularizados) ${ }^{19}$, además de la biblioteca, la escuela de gramática, los lugares para la caridad y asistencia. Así, en la sala capitular de la catedral de Pamplona creó su capilla funeraria Arnaldo de Barbazán (1318$\left.1355^{\dagger}\right)$, como hizo igualmente Álvaro de Isorna (1445-1449†) en la compostelana o Nicolás de Aguilar (1361-1370) en la murciana, asociando así uno de los espacios capitulares más significativos a la memoria del obispo ${ }^{20}$.

Los prelados más cultos y mejor formados se preocuparon (y así se constata en sus sínodos) por el nivel cultural del clero de su diócesis ${ }^{21}$, especialmente el catedralicio, y promovieron diferentes espacios del saber ligados a su catedral, como librerías, caso del ya citado Pedro Tenorio en Toledo, Alonso de Valdivieso (1485-1500†) en León o Pedro Díaz de Toledo (1487$1494 \dagger$ ) en Málaga, legándoles además sus libros ${ }^{22}$. También crearon escuelas

${ }^{16}$ Calvo 2016, p. 140, n. 32. En la renovación o sustitución de las mezquitas en more christiano fue a menudo fundamental la iniciativa de los prelados, como sucedió en Murcia con el obispo Fernando de Pedrosa (1383-1402) desde 1394.

${ }^{17}$ Entre otros, Sánchez-Palencia 1988; Olivares 2013.

${ }^{18}$ Yuste, Passini 2011.

${ }^{19}$ Como el de la catedral de Pamplona, que mantuvo los espacios de vida común, como el dormitorio y el refectorio, que tenía derecho a usar también el obispo, Goñi 1979, vol. I, pp. 468-470.

${ }^{20}$ Martínez de Aguirre 2018; Cendón 1995; Torres 1998, p. 671.

${ }^{21}$ Algunos se preocuparon también por una instrucción más directa, elaborando manuales doctrinales en romance para uso de los clérigos que no sabían latín, como hicieron Arnaldo de Barbazán y Pedro de Cuéllar, obispo de Segovia (1324-1350); García 1992.

${ }^{22}$ Campos, et al. 2013. 
de diverso tipo ${ }^{23}$, como la de gramática de Segovia, impulsada por Enrique IV y por el obispo Juan Arias Dávila (1461-1497†) ${ }^{24}$, varias de las cuáles serían el germen de futuras universidades, labor en la que muchos prelados hispanos participaron activamente con la fundación de colegios, como el salmantino de San Bartolomé por Diego de Anaya (1392-1407), los vallisoletanos de San Gregorio por Alonso de Burgos, obispo de Palencia (1485-1499†) y de Santa Cruz por el cardenal Mendoza (1473-1495†), los creados por Alonso de Fonseca (1475-1534†) en Santiago de Compostela y Salamanca o el importantísimo y ampliamente estudiado colegio boloñés fundado por Gil de Albornoz ${ }^{25}$.

En otros casos los intereses de los prelados se decantaron por el ejercicio de una caridad institucionalizada a través de hospitales, albergues, leproserías y otros centros vinculados a la catedral y generalmente gestionados por el cabildo, pero con participación de los obispos dentro de sus obligaciones pastorales, lo que se tradujo en obras como la puerta del Mollete de la catedral toledana -en la que se repartía el pan de los pobres-, que ostenta el escudo del arzobispo Sancho de Rojas $(1415-1422 \dagger)^{26}$ o las pinturas de la Pía almoina ilerdense, en las que, entre otros patrocinadores de la limosna, se representaron su obispo, Pere Sarroca (1299-1308†), y el hermano de este, Jaume, obispo de Huesca (1273-1290†) 27 .

Además, el papel que estos pobres tuvieron en la sociedad medieval, como facilitadores del ejercicio de la caridad y proveedores de oraciones por las almas de quienes les favorecieron, les otorgaron un importante protagonismo en la creación de una imagen virtuosa del prelado, como ha estudiado la Dra. Sánchez Ameijeiras, en la representación del reparto del "pan del obispo" en los sepulcros de los obispos leoneses Rodrigo Álvarez (1208-1232 $\dagger$ y Martín Rodríguez (1238-1242 $\uparrow)^{28}$, modelo para otros, como el del obispo Hernando en la catedral de Ávila (1290-1292† $)^{29}$; no olvidemos igualmente que algunos prelados eligieron precisamente un hospital de su fundación como lugar de enterramiento, como Lope de Ba-

${ }^{23}$ El Papado favoreció la creación de escuelas catedralicias en los concilios de Roma (1079) y Letrán (1179 y 1215) y el control, a través de la licentia docendi, de enseñar en estas y otras. Guijarro 2008, p. 449.

${ }^{24}$ Juárez 2015.

${ }^{25}$ En la Corona de Aragón la aparición de centros universitarios se debió más a la iniciativa regia, con el apoyo -Lleida- o rechazo - Barcelona- del gobierno municipal, aunque los prelados tuvieron cierto protagonismo en su gestión. Busqueta, Pemán 2002.

${ }^{26}$ Herráez 2013, p. 81.

${ }^{27}$ Fernández 2003, pp. 100, 105-106.

${ }^{28}$ Sánchez 1988, p. 84. Herráez 2001, p. 189 ha señalado la relación de esta iconografía, empleada por vez primera en el sepulcro del obispo Rodrigo Álvarez, con el reparto de limosnas en el aniversario del prelado.

${ }^{29}$ Caballero 2007, pp. 118-128. 
rrientos, obispo de Cuenca (1445-1469†) en el de la Piedad de Medina del $\mathrm{Campo}^{30}$.

\subsection{La liturgia, el culto y sus dispositivos: mobiliario, ornamen- tos y usos litúrgicos}

Otra relevante vía de investigación, complementaria de la anterior, es la centrada en el contenido de los edificios catedralicios, tanto el material -reliquias, mobiliario, ornamentos y objetos litúrgicos-como el inmaterial -la celebración de un ritual casi continuo que diferenciaba a la iglesia mayor de las restantes de la diócesis-. De su corrección, adecuación y decoro era responsable el prelado, además de desarrollar en la catedral una liturgia específica relacionada con sus competencias exclusivas y materializada en el pontifical, recogido en el libro que regulaba el desarrollo de estas ceremonias y los objetos necesarios para ellas, al que dedica parte de su estudio en este monográfico el Dr. Iglesias-Fonseca. Es esta una fuente que aporta una amplísima información sobre la dimensión litúrgica de obispos y arzobispos ${ }^{31}$, como el magnífico ejemplar usado por Luis de Acuña (1449-1495†), personaje estudiado en este volumen por la Dra. Cosmen, una de cuyas iniciales ilustra la portada.

Por lo general estos dispositivos litúrgicos han atraído la atención de los investigadores por su propia significación material y artística, y en ese marco se ha profundizado en su comitencia que, evidentemente, no siempre es episcopal, puesto que su realización quedaba dentro de las competencias del canónigo obrero y su mantenimiento y protección de las del tesorero. Aun así, obispos y arzobispos impulsaron frecuentemente su encargo o compra; por ejemplo, la realización de los grandes retablos de alabastro de las catedrales de Tarragona y Zaragoza, cuyas mitras ostentó sucesivamente Dalmau de Mur (1419-1431-1456†), para los que contó con artistas insignes, singularmente Pere Joan, pero también Francí y Antón Gomar, quienes realizaron igualmente por su encargo la sillería coral de Zaragoza y, ya solo Francí, la de Tarragona sobre el modelo de la anterior ${ }^{32}$, obras insignes que muestran cómo el patronazgo episcopal favoreció enormemente la transferencia de artífices, modelos y formas entre las sedes que jalonaron el cursus honorum de los prelados. Retablos de comitencia episcopal son también, entre otros, las grandes

\footnotetext{
${ }^{30}$ Villaseñor 2018 recoge igualmente su lauda sepulcral en la catedral conquense, que regentaba a su muerte.

${ }^{31}$ Palazzo 1999; López-Mayán 2014.

${ }^{32}$ Criado 2012-2013.
} 
máquinas tardogóticas de las catedrales de Sevilla y Toledo, recientemente estudiadas por las Dras. Laguna y Heim, respectivamente ${ }^{33}$.

En cuanto a las sillerías corales, la presencia de heráldica episcopal en muchas de ellas habla de su implicación, generalmente económica, confirmada documentalmente en el caso de las sillas bajas del coro toledano promovidas por su arzobispo, Pedro González de Mendoza, que desarrolló en sus dorsales todo un discurso visual de glorificación propia y de los monarcas ${ }^{34}$. Igualmente sucede con otras obras de acondicionamiento del espacio coral, como los cerramientos o las rejas; así, el arzobispo Pedro Tenorio encargó las costaneras corales de la catedral toledana o el también arzobispo Arnau Sescomes (1334-1346†) hizo lo propio con las pinturas del cerramiento coral de la catedral de Tarragona, obras que ponen de manifiesto el interés de ambos prelados por crear en este espacio fundamental un discurso visual acorde con sus intereses ${ }^{35}$.

En una escala más reducida se ha ido avanzando en el conocimiento de otras piezas relevantes, como los ornamentos y vestiduras litúrgicas. Los obispos no fueron ajenos a la relevancia de estas piezas, que compraron, encargaron, atesoraron en sus cámaras y capillas y donaron en vida o legaron en testamento, muy frecuentemente, a sus catedrales, generalmente en relación con sus devociones, intereses y gustos personales, ya que su objetivo no era únicamente la dotación de los objetos necesarios para el culto, sino favorecer la permanencia de su memoria en este a través de unos bienes de gran visibilidad. En este volumen la Dra. Cosmen recoge las vestiduras donadas por Luis de Acuña a su primera sede segoviana (1449-1456), como muestra de los primeros estadios de un patronazgo artístico que se manifestará en todo su esplendor en la burgalesa, final de su carrera eclesiástica.

Los textiles, por desgracia mal conservados y poco conocidos ${ }^{36}$, fueron a menudo legados por los prelados a sus catedrales, especialmente a la última, en la que además solían enterrarse y se convertía así en depositaria de su memoria. Tampoco era infrecuente que dejasen en testamento dinero para comprar o hacer este tipo de vestiduras, incluso materiales o piezas incompletas, como cenefas bordadas o paños sin trabajar, en un tipo de dispositivos en los que era habitual el reciclaje. En todos estos tejidos fue sumamente frecuente incluir las armas del legatario que, como en el caso de la orfebrería, se mantenían cuando la pieza se rehacía.

${ }^{33}$ Laguna, Guerra, Rodríguez 2016; Heim 2003.

${ }^{34}$ Entre otros, Teijeira 2014.

${ }^{35}$ Franco 1987; Buttà 2014.

${ }^{36}$ Algunos de ellos se han analizado en relación con su restauración, con interesantes resultados. Veáse, por ejemplo, Mantilla de los Ríos 1995. 
Los prelados aprovecharon así la suntuosidad, la magnificencia, el simbolismo y el impacto de la puesta en escena de la liturgia para poner de manifiesto el protagonismo de su nombre que, a través de su heráldica, circulaba por la catedral, incluso por la ciudad. Su memoria se hacía visible de una manera dinámica, viva, en estas ocasiones, de ahí que las piezas más relevantes que los prelados destinaron a su catedral llegaran a esta con restricciones de uso: las fiestas de mayor relevancia, los oficiantes del altar mayor o prelados de la mayor jerarquía.

El estudio de las piezas materiales, que aún debe ser más profundo y extenso, ha favorecido también el conocimiento de los bienes inmateriales, al que ha contribuido no poco el análisis de muchas fuentes documentales inéditas o nuevamente transcritas. El reciente trabajo sobre los consuetudinarios catedralicios de la corona aragonesa ${ }^{37}$, los mencionados estudios sobre los pontificales castellanos, la publicación de obituarios, libros de aniversarios, inventarios, testamentos ${ }^{38}$, etcétera han ampliado nuestro conocimiento de un mundo perdido que, en parte, ha querido reconstruirse en modernas performances, más o menos rigurosas, pero que permiten valorar la importancia de sus valores sensoriales, especialmente la presencia, fundamental, de la música, sobre la que se han hecho aportaciones realmente significativas ${ }^{39}$.

En este capítulo no debemos olvidarnos de los libros litúrgicos. No solo eran el instrumento que aseguraba el correcto desarrollo de un ceremonial amplio y complejo, sino que constituían en sí mismos una herramienta fundamental al servicio de la defensa de la ortodoxia religiosa, que correspondía en última instancia al prelado, y de su autoridad. Tengamos en cuenta la movilidad del libro, que facilitaba la extensión de su contenido escrito, pero también de las formas y técnicas empleadas para ilustrarlo. El movimiento de los prelados ibéricos en época bajomedieval, incluso sus viajes formativos a universidades foráneas, les pusieron en contacto directo con los talleres de producción libraria más vanguardistas y a través de ellos llegaron a la península obras tan relevantes como el pontifical de Juan de Villacreces, obispo de Calahorra y Burgos (1390-1394-1406), realizado en el taller aviñonense de Jean de Toulouse, o el del obispo de Valencia Vidal de Blanes $(1356-1369 \dagger)^{40}$.

\footnotetext{
${ }^{37}$ Carrero 2014a.

${ }^{38}$ Teijeira 2018.

${ }^{39}$ Ruiz 2017; Rodilla, et al. 2019.

${ }^{40}$ López-Mayán 2014, pp. 151-153; Miquel 2009, p. 324.
} 


\subsection{El prelado en la ciudad: el palacio episcopal}

Como ya se ha comentado, la configuración y difusión de la imagen del poder episcopal muestra su desarrollo más evidente en escenarios relacionados con la autoridad religiosa, como la catedral, pero también otros templos de su diócesis. Véase, por ejemplo, el artículo de los Dres. Cendón y Chao sobre la impronta de la catedral compostelana en otras iglesias del territorio de la mitra, a instancias precisamente de su arzobispo Lope de Mendoza (1400-1445†). Además, el prelado es igualmente cabeza de una poderosa institución cuya imagen se expresa, por ejemplo, en las moradas episcopales, desigualmente conocidas ${ }^{41}$, que entremezclan el ámbito de lo personal -como residencia privada del prelado y sus "familiares"-y de lo público -como sede oficial de la curia episcopal-. En el primer aspecto se evidencia en ellas el lujo inherente a un príncipe de la iglesia, incluyendo la presencia de un ceremonial y un personal imprescindibles para el gobierno de la casa, pero también para proporcionar la correspondiente magnificencia a la imagen del obispo; en el segundo las estancias y el personal suficiente y debidamente formado para gestionar todos los asuntos temporales de la mitra. En este segundo ámbito, más público, debemos tener en cuenta las múltiples facetas del poder episcopal para poder comprender la complejidad de la curia, aún poco conocida a pesar de las meritorias aportaciones de recientes investigaciones ${ }^{42}$.

Además de sus otras residencias institucionales, incluidas las fortalezas que protegían el señorío, y de sus casas privadas, la principal vivienda del obispo era, evidentemente, el palacio episcopal en la cabeza de la sede. $\mathrm{Su}$ carga representativa fue en ocasiones la razón de su mala conservación, incluso de su destrucción en el marco de los conflictos entre el prelado y otros poderes, como sucedió en Córdoba, en Pamplona o en Palencia ${ }^{43}$. La frecuencia de estos enfrentamientos determinó además que gran parte de estos palacios estuvieran más cerca de la fortaleza que del palacio, como puede verse aún en el de Gerona, o como en el caso de Sigüenza, donde los obispos utilizaron como residencia el castillo durante todo el periodo medieval y moderno ${ }^{44}$. No sería hasta fines de la época medieval, en el mejor de los casos, cuando pierdan este carácter de fortaleza para adquirir un aspecto más palaciego.

\footnotetext{
${ }^{41}$ Obra de referencia fundamental para el caso ibérico es Carrero 2007.

${ }^{42}$ Cárcel 1998; Cañas 2015, 2019.

${ }^{43}$ Sanz 2005; Martínez de Aguirre 2018; Culebras 2008, pp. 233-234.

${ }^{44}$ Martínez 1985.
} 
De su construcción o reforma se encargaron evidentemente los prelados, financiando las obras de su peculio institucional ${ }^{45}$; por desgracia las obras continuarían en la mayoría de ellos en época moderna y contemporánea, quedando escasos restos de los edificios medievales. En muchos de ellos, generalmente cercanos a la catedral, incluso comunicados con ella, se mantiene aún la impronta de aquellos prelados que coadyuvaron a la magnificencia de un edificio en el que el obispo quiso mostrar la relevancia de su prelatura y de sus acciones particulares, como sucede en el palacio episcopal compostelano, estudiado en este volumen por el Dr. Moráis a través de las aportaciones de dos de sus arzobispos, o el oscense, en cuyo salón del "Tanto monta" encontramos, además de la heráldica y la paraheráldica obispal, entre otras las del obispo Antonio de Espés (1470-1484†), diversas figuras de obispos y cardenales talladas en las jácenas de la cubierta ${ }^{46}$.

\section{LOS INTERESES DE LOS PRELADOS Y SU TRASCENDENCIA ARTÍSTICA}

Además de la configuración de una imagen de poder difundida, entre otros medios, a través de la producción artística, que los prelados consideraron parte importante de lo que debían a su "estado", muchos obispos y arzobispos encargaron obras que obedecían a intereses más personales, incluso aunque estos se desarrollasen igualmente en el plano institucional. En ellas los investigadores han encontrado motivaciones, necesidades y deseos que se vinculan a la personalidad y trayectoria de cada prelado y que se recogen en varios de los estudios particulares del bloque tercero.

Entre estos intereses quizá el principal fue la muerte, que centra la atención de los Dres. Serrano y Boto, por un lado y Fernández-Ladreda por otro, además de estar igualmente presente en los de los Dres. Bock, Cosmen y Moráis.

\subsection{La muerte del obispo: capillas funerarias, sepulcros y litur- gia fúnebre}

La profunda preocupación por la muerte y el destino del alma tras esta han sido ampliamente estudiados para el periodo bajomedieval,

\footnotetext{
${ }^{45}$ En ocasiones se desviaron fuentes habituales de financiación de obras catedralicias para la mejora de los palacios episcopales, como sucedió en Córdoba en el episcopado de Íñigo Manrique de Lara (1485-1496†): Sanz 2005, p. 257.

${ }^{46}$ Villacampa 2018.
} 
igualmente las importantes empresas artísticas con ellos vinculadas y destinadas a un doble objetivo: asegurar la permanencia de la memoria del difunto y atraer oraciones para garantizar su salvación. Se activaron así una serie de dispositivos artísticos que constituyen uno de los aspectos del patronazgo bajomedieval que tradicionalmente ha acaparado más atención por parte de los investigadores ${ }^{47}$, especialmente los bienes materiales a que dio lugar dicha preocupación: capilla funeraria y sepulcro ${ }^{48}$.

Por lo que respecta al arte funerario de patronazgo episcopal, ha habido un cierto retraso en su estudio con respecto a otros comitentes, como los reyes o la nobleza. Los relevantes estudios de, entre otros, la Dra. Cendón ${ }^{49}$, que interviene en el presente volumen, han puesto de manifiesto que para obispos y arzobispos, como para otros personajes ilustres, el tránsito de la muerte constituyó una preocupación cardinal y la base de algunas de sus más significativas aportaciones artísticas. Ciertamente lo tenían más fácil que otros en cuanto que su cargo eclesiástico les proporcionaba un espacio privilegiado al que no todos tuvieron acceso, al menos en un principio. No fue pues extraño que se crearan panteones episcopales en las catedrales góticas hispanas, como el temprano de la catedral leonesa o el de la catedral de Tarragona ${ }^{50}$.

Los prelados tomaron posesión de los espacios más relevantes del templo catedralicio o bien crearon sus propias capillas funerarias privativas ex novo, acondicionándolas además con las habituales piezas litúrgicas -retablo, vidrieras, rejas, pinturas murales, ornamentos y vestiduras y paños-, en torno a un sepulcro más o menos monumental; además, las dotaron para el desarrollo ad eternum de una liturgia fúnebre por su alma. Evidentemente, ello no redundó solo en beneficio del finado, sino que contribuyó a la magnificencia del templo, al reforzamiento del poder de la catedral y de su identidad corporativa, al enriquecimiento de su actividad litúrgica y a la ampliación de su acción caritativa con los legados para limosnas y retribuciones.

Espacios, monumentos funerarios, ornamentos y liturgia fúnebre han sido estudiados por diversos investigadores como expresión de una actitud ante la muerte que decía mucho de lo que el difunto había sido en vida y de cómo deseaba proyectar esa presencia más allá del momento de su desaparición. Gracias a estos estudios conocemos con cierta profundidad el proceso, al menos material, de ejecución de muchas obras conservadas, así como documentación que nos permite acercarnos a aquellos otras, innumerables, que se han perdido. Veremos algunos ejemplos en la segunda y tercera parte de este volumen.

\footnotetext{
${ }^{47}$ Núñez, Portela 1988, 1992; Bock, Foletti, Tomasi 2014.

${ }^{48}$ Bango 1992; Yarza 1988.

${ }^{49}$ Cendón 2006, 2007.

${ }^{50}$ Sánchez 2000; Serrano, Boto 2018.
} 
De ellos podemos deducir que lo primero que los prelados tenían en consideración al realizar sus disposiciones post mortem era la elección del lugar en el que querían ser enterrados, habitualmente recogido en su testamento y que era frecuentemente la catedral de su última diócesis - el templo más que el claustro, territorio capitular- ${ }^{51}$. En la iglesia, presbiterio y coro eran los espacios más ambicionados, en un proceso de acercamiento progresivo al altar mayor que había comenzado a principios del siglo XIII, cuando Pedro Muñiz, arzobispo de Compostela (1207-1224†), se enterró a los pies del parteluz del Pórtico de la Gloria y que culminó con otro arzobispo, en este caso toledano, Pedro González de Mendoza, que al final del medievo monopolizó el muro del evangelio del presbiterio de su catedral para su sepultura ${ }^{52}$. El coro menor de la primada fue igualmente elegido por varios arzobispos, entre ellos Gómez Manrique (1362-1375†) que, como cuenta el Dr. Moráis en su artículo, desechó la capilla funeraria que había iniciado en el claustro compostelano para descansar a los pies del altar de la Virgen Blanca. Paralelamente, se fue haciendo más frecuente la creación de capillas privativas, usando las de la girola, las creadas entre contrafuertes y otros espacios de las naves o construidas de nuevo, como muestran los ejemplos de Bernat de Pau (1436-1457) y su sobrino Joan Margarit (1462-1484†) en la catedral de Girona, de Gil de Albornoz y Sancho de Rojas en la toledana o de Juan de Cervantes (1448-1453†) en la sevillana ${ }^{53}$. Aunque muchas se han estudiado aún es más lo que nos queda por conocer.

El protagonismo en estos espacios era evidentemente para el monumento funerario. Los obispos y arzobispos bajomedievales utilizaron las tipologías habituales: lauda a ras del suelo, sepulcro murario con o sin lucillo o exento, en una trayectoria que suele ir cronológicamente de menos a más en cuanto a dimensiones, presencia de figuración y complejidad temática, existencia de yacente u orante, elaboración de epitafios, heráldica, etcétera. $\mathrm{Su}$ desarrollo figurativo ha favorecido también su estudio en el contexto de la trayectoria de artistas concretos y su relación con sus comitentes, o de la elección no casual de materiales y técnicas ${ }^{54}$, incluso del recuerdo de las arquitecturas efímeras y los textiles y ornamentos utilizados durante las ceremonias fúnebres en su estructura ${ }^{55}$. La existencia de un discurso visual generalmente

\footnotetext{
${ }^{51}$ No deja de haber ejemplos de obispos que crearon su capilla funeraria en el claustro de su catedral, como Juan Lucero (1339-1361) y Diego de Anaya (1392-1407) en la catedral de Salamanca; véanse Gutiérrez 2020; Cosmen 2019, respectivamente.

${ }^{52}$ Carrero 2014b, p. 181; Teijeira 2019.

${ }^{53}$ Prats 1994; Molina 2006; Marías, Serra 2005; Herráez 2013; Laguna 2018.

${ }^{54}$ Como sucede con el uso de materiales pétreos especiales, como la piedra del sepulcro del obispo de Girona Berenguer de Anglesola (1384-1408†), recogida en el contrato con Pere Oller que finalmente no se materializó (Valero 2004, pp. 702-704). En general Español, Valero 2017.

${ }^{55}$ Pérez 2011.
} 
complejo, como el desarrollado en los sepulcros de Miguel Sánchez Asiáin (1357-1364†) en la catedral de Pamplona, o el de Juan de Aragón (1328$1334 \dagger$ ) en la primada tarraconense, cuyos estudios en este volumen debemos a los Dres. Fernández-Ladreda y Boto y Serrano respectivamente, nos muestra los intereses espirituales de estos personajes, buenos conocedores, muchos de ellos, de las sutilezas teológicas que coetáneamente se estaban debatiendo sobre el destino del alma tras la muerte.

Me gustaría destacar, con respecto a los estudios más recientes, el uso de las nuevas tecnologías de análisis y reconstrucción virtual para reproducir detalles hoy perdidos, como la magnífica policromía del paño mortuorio de Juan de Cervantes en la catedral de Sevilla o la organización de los monumentos funerarios del panteón episcopal de la capilla de San Agustín en la catedral de Tarragona. Igualmente, la apertura de sepulcros, en el marco de su restauración, ha permitido conocer detalles de gran interés, como las vestiduras de Jiménez de Rada, o los objetos encontrados en la tumba de Alonso de Aragón, arzobispo de Zaragoza (1478-1520 $\uparrow)^{56}$. Todo ello ha ampliado de manera exponencial nuestro conocimiento de algunas de estas obras, manifestando un potencial para la investigación futura difícil de valorar, pero desde luego muy prometedor.

También se está trabajando en los últimos años, con interesantes resultados, en la parte más desconocida de estos proyectos episcopales: la elaboración de una liturgia destinada a mantener la memoria del difunto y ayudar a la salvación de su alma, utilizando para ello auténticos dispositivos performáticos en la celebración periódica de aniversarios, misas o liturgia estacional centralizada en la capilla-sepulcro, incluyendo los objetos litúrgicos necesarios, los capellanes que la atendieran y, por supuesto, todo el complejo administrativo que gestionase los bienes destinados a cubrir los gastos ${ }^{57}$. Esta liturgia prolongaba en el tiempo las celebraciones religiosas del funeral y tenía su expresión gráfica en los relieves de los propios sepulcros, a través, por ejemplo, de los petrificados plorantes del sepulcro realizado por Pere Moragues para el arzobispo Lope Fernández de Luna (1351-1380†) en la catedral de Zaragoza, o de los que reproducen el funeral de Gonzalo de Hinojosa en la burgalesa ${ }^{58}$.

Muestra de un interés más personal, muchos prelados decidieron enterrarse en otros templos, como Pablo de Santamaría, obispo de Burgos (1415$1435 \dagger$ ), que eligió el convento de San Pablo de esta ciudad, seguramente por su estrecha relación con la orden dominica, o el franciscano Juan Enríquez, obispo de Lugo (1409-1418†), en Santa Clara la Real de Toledo ${ }^{59}$. Pero también llama-

\footnotetext{
${ }^{56}$ Naya 2017.

${ }^{57}$ Véase por ejemplo Pérez 2011; Teijeira 2019.

${ }^{58}$ Lacarra 1998; Gómez 1988, p. 67.

${ }^{59}$ Respectivamente Casillas 2002; Cendón 2005, pp. 925-929.
} 
ba la sangre y no son raros los obispos que promovieron un panteón familiar; es el caso de Juan Rodríguez de Fonseca, obispo sucesivamente de Badajoz, Córdoba, Palencia y Burgos (1495-1499-1504-1514-1524†), en la reedificada iglesia de Santa María de Coca, junto con, entre otros, su tío el arzobispo Alonso de Fonseca y Ulloa; si los familiares junto a los cuales se iba a pasar la eternidad eran santos la elección era mucho más clara; así sucedió con Rodrigo Jiménez de Rada, quien tras iniciar la fastuosa catedral gótica de Toledo prefirió esperar el juicio en el monasterio cisterciense de Huerta, junto a su tío San Martín de Hinojosa $^{60}$. En estos casos se potencia el mantenimiento no solo del nombre propio, sino de un linaje orgulloso de sus logros, no en vano gran parte de nuestros obispos y arzobispos procedían de familias de la nobleza.

\subsection{Los intereses suntuarios: dispositivos episcopales}

Probablemente la insistencia de los prelados en establecer mecanismos que asegurasen la salvación de sus almas derivase del convencimiento de que estas no podrían salvarse por sí mismas, dada la escasa vocación religiosa de la mayoría. Esto nos lleva a recoger intereses más terrenales que se plasmaron igualmente en su patronazgo artístico.

Como miembros relevantes de la iglesia y significativas figuras de poder llevaron una vida lujosa y solemne, que se manifestó no solamente en su ámbito público, sino también en el privado, en los objetos de su cámara y capilla, cuyo volumen, complejidad y riqueza crecieron de manera importante desde el siglo XIV y que conocemos especialmente a través de la documentación generada por sus legados o por sus expolios ${ }^{61}$.

La cámara (permanente y de viaje) contenía ropas, mobiliario, textiles, objetos artísticos y libros. La capilla conservaba los objetos litúrgicos necesarios para el desarrollo del culto en el oratorio privado del prelado -ornamentos, vestiduras, retablos e imágenes, relicarios y libros litúrgicos-. Los inventarios realizados a la muerte de los prelados nos muestran el interés de la mayoría por el uso, en una y otra, de objetos suntuarios que no solo expresan el deseo de rodearse de un entorno lujoso, propio de su cargo, sino también un gusto artístico a menudo refinado y actualizado, en objetos comprados en los principales centros de producción peninsulares y europeos -directamente o importados- o encargados expresamente a artistas locales o foráneos: piezas de oro y plata como los 125 objetos de vajilla, algunos esmaltados y con su heráldica, inventariados a la muerte de Alonso de

\footnotetext{
${ }^{60}$ Vasallo 2018, pp. 235-239; López de Guereño 2007.

${ }^{61}$ Saraiva 2001-2002.
} 
Valdivieso, obispo de León ${ }^{62}$; las armaduras que tenía Juan de Serrano, obispo de Sigüenza (1389-1402†), para sí mismo y su séquito ${ }^{63}$; textiles como los legados por Juan Arias Dávila a la catedral segoviana ${ }^{64}$; retablos como el encargado por Dalmau de Mur para el palacio episcopal de Zaragoza ${ }^{65}$ o libros como los que el papa Luna se procuró en las disposiciones testamentarias que él mismo estableció a la muerte de su sobrino Pedro de Luna, arzobispo de Toledo $(1407-1414 \uparrow)^{66}$. Un ejemplo excepcional, que conocemos documentalmente, debió ser el contenido de la cámara de Pedro Gónzalez de Mendoza ${ }^{67}$. Muchos de estos objetos acabarían en las catedrales de sus sedes, donados en vida o legados a su muerte, enriqueciendo de este modo el tesoro, la sacristía o la librería catedralicios y manteniendo viva la memoria de los prelados en la actividad cotidiana del templo.

Todo lo dicho podría aplicarse del mismo modo a otros patronos relevantes no pertenecientes al estamento eclesiástico, por lo que ¿qué caracteriza al patronazgo episcopal? Evidentemente el prelado representa a una institución religiosa y si bien adoptaría, a lo largo de la Baja Edad Media, recursos y dispositivos tomados de otros comitentes, le interesaba destacar, por encima de todo, su figura como eclesiástico y su relevancia como patriarca, cardenal, primado, metropolitano, arzobispo u obispo. Asumió, por lo tanto, y así debe verse en sus realizaciones, la magnificencia, suntuosidad y autoridad propia del cargo que ostentaba, así como su vinculación a lo sagrado, puesto que este era el origen de su poder.

De hecho, seis o siete siglos después de su muerte, todavía seguimos recordándolos, investigando sus vidas, sus acciones, sus intereses; si bien ya pocos sufragios por su alma atraerán, la memoria de lo que supusieron en su época sí se ha mantenido activa, al menos en estos once capítulos que dedicamos a sus proyectos artísticos y que esperamos desencadenen nuevos análisis sobre otros prelados, aún poco conocidos, que están aguardando a quien recupere su memoria.

MARÍA DOLORES TEIJEIRA PABLOS

Instituto de Estudios Medievales. Universidad de León

MARÍA ViCTORIA HERRÁEZ ORTEGA

Instituto de Estudios Medievales. Universidad de León

\footnotetext{
${ }^{62}$ Zaragoza 1995, pp. 226-228.

${ }^{63}$ Cañas 2019.

${ }^{64}$ Teijeira 2018, p. 286.

${ }^{65}$ Ibáñez 2012.

${ }^{66}$ Pavón 2018.

${ }^{67}$ Franco 2012.
} 


\section{BIBLIOGRAFÍA CITADA}

Alcoy, Rosa; Allion, Dominique; Bilotta, Maria Alexandra; Gianandrea, Manuela (eds.) (2012), Le Plaisir de l'art: Commande, production et réception de l'œuvre d'art. Mélanges en hommage à Xavier Barral $i$ Altet, París, Picard.

Aurell, Martin; García de la Borbolla, Ángeles (2004), La imagen del obispo hispano en la Edad Media, Barañáin, Eunsa.

Bango Torviso, Isidro (1992), El espacio para enterramientos privilegiados en la arquitectura medieval española, "Anuario del Departamento de Teoría e Historia del Arte" 4, pp. 93-132.

Bock, Nicolas; Foletti, Ivan; Tomasi, Michele (2014), L'évêque, l'image et la mort. Identité et mémoire au Moyen Âge, Roma, Viella.

Boto, Gerardo; Escandell, Isabel; Lozano, Esther (eds.) (2019), The Memory of the Bishop in Medieval Cathedrals. Ceremonies and Visualizations, Berna, Peter Lang.

Busqueta i Riu, Joan Josep; Pemán Gavín, Juan María (coords.) (2002), Les universitats de la Corona d'Arago, ahir $i$ avui. Estudis historics, Barcelona, Pòrtic.

Buttà, Licia (2014), Un maestro para el ciclo de la Vera Cruz: nuevas observaciones sobre las pinturas murales del trascoro de la catedral de Tarragona, "Medievalia" 17, pp. 9-38.

Caballero Escamilla, Sonia (2007), La escultura gótica funeraria de la catedral de Ávila, Ávila, Institución Gran Duque de Alba.

Calvo Capilla, Susana (2016), De mezquita a iglesia: el proceso de cristianización de los lugares de culto de Al-Andalus, en Giráldez, Pilar; Vendrell, Màrius (coords.), Transformació, destrucció i restauració dels espais medievals, Barcelona, Patrimoni 2.0 editors, pp. 129-148.

Campos Sánchez-Bordona, María Dolores; Carrero Santamaría, Eduardo; Suárez González, Ana; Teijeira Pablos, María Dolores (2013), Librerías catedralicias. Un espacio del saber en la Edad media y moderna, Santiago de Compostela - León, Universidad de Santiago de Compostela - Universidad de León.

Cañas Gálvez, Francisco de Paula (2015), La casa y corte del obispo abulense Sancho Blázquez Dávila: un modelo curial episcopal castellano a mediados del siglo XIV, "Espacio, tiempo y forma. Serie III. Historia medieval" 28, pp. 133-157.

Cañas Gálvez, Francisco de Paula (2019), La Casa de Juan Serrano, obispo de Sigüenza: articulación funcional y escenarios domésticos en la corte de un prelado castellano, en Cañas Gálvez, Francisco de Paula; Nieto Soria, José Manuel (coords.), Casa y Corte. Ámbitos de poder 
en los reinos hispánicos durante la Baja Edad Media (1230-1516), Madrid, La Ergástula, pp. 249-290.

Cárcel Ortí, María Milagros (1998), Casa, corte y cancillería del obispo de Valencia Hug de Llupià (1398-1427), "Anuario de Estudios Medievales" 28/1, pp. 635-659.

Carrero Santamaría, Eduardo (2007), Le palais épiscopal dans les royaumes ibériques médiévaux. Une interprétation fonctionnelle, "Hortus artium medievalium" 13/1, pp. 183-202.

Carrero Santamaría, Eduardo (coord.) (2014a), Arquitectura y liturgia. El contexto artístico de las consuetas catedralicias en la Corona de Aragón, Palma de Mallorca, Objeto perdido.

Carrero Santamaría, Eduardo (2014b), Arzobispos y obras en Santiago de Compostela entre los siglos XII y XIII. La definición del espacio litúrgico en la catedral, en Teijeira Pablos, María Dolores; Herráez Ortega, María Victoria; Cosmen Alonso, María Concepción (eds.), Reyes y Prelados. La creación artística en los reinos de León y Castilla (1050-1500), Madrid, Sílex, pp. 173-201.

Casillas García, José Antonio (2002), Los enterramientos en el convento de San Pablo de Burgos, "Archivo Dominicano" 23, pp. 219-306.

Caskey, Jill (2006), Whodunnit? Patronage, the Canon and the Problematics of Agency in Romanesque and Gothic Art, en A Companion to Medieval Art. Romanesque and Gothic in Northern Europe, Oxford, Blackwell Limited Publishing, pp. 287-307.

Cendón Fernández, Marta (1995), El sepulcro del arzobispo don Álvaro de Isorna en la catedral de Santiago, "Cuadernos de Estudios Gallegos" 42/107, pp. 209-226.

Cendón Fernández, Marta (2005), Yacentes de obispos franciscanos en época de los Trastámara, en El franciscanismo en la Península Ibérica: balance y perspectivas. I Congreso Internacional, Barcelona, GBG Editora, pp. 917-934.

Cendón Fernández, Marta (2006), El poder episcopal a través de la escultura funeraria en la Castilla de los Trastámara, "Quintana" 5/5, pp. 173-184.

Cendón Fernández, Marta (2007), El obispo ante la muerte en la Castilla de los Trastámara, "Archivo Ibero-Americano" 67, pp. 677-708.

Cosmen Alonso, María Concepción (2019), Memoria de Diego de Anaya y Maldonado (†1437). Ilustración, crítica y devoción, en Boto, Gerardo; Escandell, Isabel; Lozano, Esther (eds.), The Memory of the Bishop in Medieval Cathedrals. Ceremonies and Visualizations, Berna, Peter Lang, pp. 463-509.

Criado Mainar, Jesús (2012-2013), El arzobispo Dalmau de Mur, los hermanos Gomar y la sillería del coro de la Seo de Zaragoza, "Lambard" 24, pp. 149-167. 
Cros, Almudena (2008), The Artistic Patronage of Gil de Albornoz (13021367), A Cardinal in Context [en línea], Coventry, University of Warwick, (tesis doctoral) Wrap.warwick.ac.uk/2732/1/WRAP THESIS_CrosGutierrez_2008.pdf [consulta: 15/12/2019].

Culebras Majolero, Noemí (2008), La morada de los obispos palentinos y el inicio del proceso de construcción de la nueva residencia episcopal tras la destrucción del Alcázar a la luz de las fuentes de archivo, "Publicaciones del Instituto Tello Téllez de Meneses" 79, pp. 229-273.

Danielson, Sigrid; Gatti, Evan (eds.) (2014), Envisioning the Bishop: Images and the Episcopacy in the Middle Ages, Turnhout, Brepols.

Díaz Ibáñez, Jorge (1998), La organización institucional de la Iglesia en la Edad Media, Madrid, Arco Libros.

Español Bertran, Francesca; Valero Molina, Joan (2017), Les pedreres medievals a la corona d'Aragó, Barcelona, Institut d'Estudis Catalans.

Fernández Somoza, Gloria (2003), Imágenes de la caridad catedralicia. Orígenes y evolución funcional de las pinturas de la Pía Almoina de Lleida, "De Arte" 2, pp. 87-125.

Franco Mata, Ángela (1987), El génesis y el éxodo en la cerca exterior del coro de la catedral de Toledo, "Toletvm" 21, pp. 53-160.

Franco Silva, Alfonso (2012), La cámara del cardenal Mendoza. Lujo, riqueza y poder de un principe de la iglesia hispana del siglo XV, "Historia, Instituciones, Documentos" 39, pp. 65-127.

García Fernández, Ernesto (1992), El catecismo medieval de Arnaldo de Barbazán, obispo de la diócesis de Pamplona, "En la España medieval" 15, pp. 321-352.

Gómez Bárcena, María Jesús (1988), Escultura gótica funeraria en Burgos, Burgos, Diputación Provincial de Burgos.

Gonzálvez Ruiz, Ramón (coord.) (2010), La catedral de Toledo. Dieciocho siglos de historia y arte, Burgos, Promecal.

Goñi Gaztambide, José (1979), Historia de los obispos de Pamplona, Pamplona, Eunsa.

Guenée, Bernard (1987), Entre l'Église et l'État. Quatre vies de prélats français à la fin du Moyen Âge, París, Gallimard.

Guijarro González, Susana (2008), El saber de los claustros: las escuelas monásticas y catedralicias en la Edad Media, "Arbor" 731, pp. 443-455.

Guijarro González, Susana (2019), Cabildos catedralicios y obispos en la Iberia medieval. Autoridad, disciplina y conflicto, Madrid, Sílex.

Gutiérrez Baños, Fernando (2020), Un obispo, una capilla, unas pinturas murales, en Gutiérrez Baños, Fernando, Las pinturas murales de la capilla de Santa Bárbara de la catedral vieja de Salamanca. Contar 
historias en la Castilla del siglo XIV, Salamanca, Catedral de Salamanca, pp. 59-76.

Heim, Dorothée (2003), Entre Mendoza y Cisneros: la gestación del retablo de la catedral de Toledo, "Anales Toledanos" 39, pp. 103-116.

Herráez Ortega, María Victoria (2001), La catedral gótica de León: el inicio de la construcción a la luz de nuevos datos y reflexiones sobre la escultura monumental, "Estudios Humanísticos. Geografía, Historia y Arte" 22, pp. 183-200.

Herráez Ortega, María Victoria (2004), La construcción del templo gótico, en Yarza Luaces, Joaquín; Herráez Ortega, María Victoria; Boto Varela, Gerardo (eds.), La Catedral de León en la Edad Media. Actas del Congreso internacional, León, Universidad de León, pp. 145-176.

Herráez Ortega, María Victoria (2013), La fundación y dotación de la capilla de San Pedro en la catedral de Toledo, "Laboratorio de Arte" 25, pp. 79-96.

Herráez Ortega, María Victoria (2018), The Episcopal Imprint in the Cathedral of San Antolin de Palencia. The construction of a Gothic Chevet (1321-1460), en Herráez Ortega, María Victoria; Cosmen Alonso, María Concepción; Teijeira Pablos, María Dolores; Moráis Morán, José Alberto (eds.), Obispos y catedrales. Arte en la Castilla bajomedieval, Berna, Peter Lang, pp. 221-257.

Herráez Ortega, María Victoria; Cosmen Alonso, María Concepción; Teijeira Pablos, María Dolores; Moráis Morán, José Alberto (eds.) (2018), Obispos y catedrales. Arte en la Castilla bajomedieval, Berna, Peter Lang.

Hourihane, Collum (ed.) (2013), Patronage, Power and Agency in Medieval Art, Princeton-College Station, Index of Christian Art.

Ibáñez Fernández Javier (2012), La capilla del palacio episcopal de Zaragoza en el contexto de la renovación del gótico final en la Península Ibérica, Zaragoza, Museo diocesano de Zaragoza.

Joubert, Fabienne (2006), L'artiste et le clerc: commandes artistiques des grands ecclésiastiques à la fin du Moyen Âge (XIV-XVIe siècles), París, Presses Paris Sorbonne.

Juárez Valero, Eduardo (2015), El estudio de Juan Arias Dávila, "Edad Media. Revista de Historia" 16, pp. 233-263.

La Seu Vella de Lleida. La catedral, els promotors, els artistes. S. XIII a S. XV (1991), Barcelona, Generalitat de Catalunya.

Lacarra Ducay, María Carmen (1998), El templo arzobispal (1318-1381), en La Seo de Zaragoza, Zaragoza, Diputación General de Aragón, pp. 125-138.

Laguna Paúl, Teresa (2018), Memoria funeraria y patronazgo de Juan de Cervantes en la catedral de Sevilla. Mercadante de Bretaña y las obras 
de la capilla de san Hermenegildo, en Herráez Ortega, María Victoria; Cosmen Alonso, María Concepción; Teijeira Pablos, María Dolores; Moráis Morán, José Alberto (eds.), Obispos y catedrales. Arte en la Castilla bajomedieval, Berna, Peter Lang, pp. 75-120.

Laguna Paúl, Teresa; Guerra Librero, Fernando; Rodríguez Trobajo, Eduardo (2016), Carpinteros y ensambladores en la estructura del Retablo Mayor de la catedral de Sevilla, en Celeste Glória, Ana (coord.), $O$ Retábulo no Espaço Ibero-Americano: Forma, Funçao e Iconografia, Lisboa, Instituto de História da Arte, pp. 261-275.

López de Guereño Sanz, María Teresa (2007), Santa María de Huerta, panteón de la nobleza castellana, "De Arte" 6, pp. 37-56.

Lopez-Mayán, Mercedes (2014), Los pontificales en Castilla durante la Edad Media: aproximación a una fuente de conocimiento histórico, en Incipit 2. Workshop de Estudos Medievais da Universidade do Porto, Porto, Universidade do Porto, pp. 141-153.

Mantilla de los Ríos y Rojas, María Socorro (coord.) (1995), Vestiduras pontificales del Arzobispo Rodrigo Ximénez de Rada. S. XIII. Su estudio y restauración, Madrid, Ministerio de Cultura.

Marías Franco, Fernando; Serra Desfilis, Amadeo (2005), La capilla Albornoz de la catedral de Toledo y los enterramientos monumentales de la España bajomedieval, en Guillaume, Jean (ed.), Demeures d'éternité. Églises et chapelles funéraires aux XV $V^{e}$ et $X V I^{e}$ siècles, París, Picard, pp. 33-48.

Martín Martínez de Simón, Elena (2013), Arquitectura religiosa tardogótica en la provincia de Burgos (1440-1511), Burgos, Universidad de Burgos (tesis doctoral).

Martínez de Aguirre Aldaz, Javier (2006), La catedral de Tudela, Pamplona, Diputación Foral - Institución Príncipe de Viana.

Martínez de Aguirre Aldaz, Javier (2018), Obispo, cabildo y monarcas ante los procesos constructivos de la catedral de Pamplona (siglos XIII $a X V$ ), en Herráez Ortega, María Victoria; Cosmen Alonso, María Concepción; Teijeira Pablos, María Dolores; Moráis Morán, José Alberto, Obispos y catedrales. Arte en la Castilla bajomedieval, Berna, Peter Lang, pp. 523-562.

Martínez Taboada, Pilar (1985), Desarrollo urbanístico de las ciudades episcopales: Sigüenza en la Edad Media, "En la España medieval" 7, pp. 957-972.

Menéndez González, Nicolás (2009), Juan de Colonia en los inicios del tardogótico burgalés, en IV Simposio internacional de jóvenes medievalistas, Murcia, Universidad de Murcia, pp. 145-160. 
Merlo, Grado Giovanni (2003), Vescovi medievali, Milán, Biblioteca Francescana.

Miquel Juan, Matilde (2009), Aviñón, foco artístico para la Valencia del siglo $X I V$. El papel del obispo Vidal de Blanes, en Cosmen Alonso, Concepción; Herráez Ortega, María Victoria; Pellón Gómez-Calcerrada, María (eds.), El intercambio artístico entre los reinos hispanos y las cortes europeas en la Baja Edad Media, León, Universidad de León, pp. 321-331.

Molina Figueras, Joan (2006), L'horitzó estètic d'un humanista catalá: Joan Margarit $i$ el triomf dels models septentrionals a la Girona del quatrocents, en Vilallonga, Mariàngela; Miralles, Eulalia; Prats, David (eds.), El cardenal Margarit i l'Europa quatrecentista, Roma, "L'Erma" di Bretschneider, pp. 35-60.

Naya Franco, Carolina (2017), El ajuar funerario del arzobispo de Zaragoza y Valencia Don Alonso de Aragón (1470-1520), "Archivo Español de Arte" 360, pp. 335-346.

Núñez, Manuel; Portela, Ermelindo (coords.) (1988), La idea y el sentimiento de la muerte en la historia y en el arte de la Edad Media, Santiago de Compostela, Universidad de Santiago de Compostela.

Núñez, Manuel; Portela, Ermelindo (coords.) (1992), La idea y el sentimiento de la muerte en la historia y en el arte de la Edad Media II, Santiago de Compostela, Universidad de Santiago de Compostela.

Olivares Martínez, Diana (2013), Albornoz, Tenorio y Rojas: las empresas artísticas de tres arzobispos de Toledo en la Baja Edad Media. Estado de la cuestión, "Estudios Medievales Hispánicos" 2, pp. 129-174.

Palazzo, Éric (1999), L'évêque et son image: l'illustration du pontifical au Moyen Âge, Turnhout, Brepols.

Pavón Ramírez, Marta (2018), La biblioteca de Pedro Martínez de Luna, arzobispo de Toledo (1403-1414) y sobrino homónimo de Benedicto XIII, en un documento inédito del Archivo Secreto Vaticano, en Der Papst und das Buch im Spätmittelalter (1350-1500), Múnich, Verlag, pp. 189-210.

Payo Hernanz, René (coord.) (2008), La catedral de Burgos. Ocho siglos de historia y arte, Burgos, Promecal.

Pérez Monzón, Olga (2011), Escenografias funerarias en la Baja Edad Media, "Códex Aquilarensis" 27, pp. 213-244.

Prats, Lluis (1994), El sepulcro de Bernat de Pau, obispo de Girona (14361457), “Annals de l'Institut de Estudis Gironins” 33, pp. 453-479.

Quintavalle, Arturo Carlo (ed.) (2011), Medioevo: I commitenti. Atti del Convegno internazionale di Studi, Milán, Mondadori Electa. 
Rodilla León, Francisco; Fenlon, Iain; Esteve Roldán, Eva; Torrente Lobo, Nuria (eds.) (2019), Sonido y espacio: antiguas experiencias musicales ibéricas, Madrid, Alpuerto.

Ruiz Jiménez, Juan (2017), Cathedral Soundscapes: Some New Perspectives, en Knighton, Tess (ed.), A Companion to Music in the Age of the Catholic Monarchs, Leiden - Boston, Brill, pp. 242-281.

Sánchez Ameijeiras, Rocío (1988), Dos ejemplos de patronazgo en la iconografia de la escultura gótica funeraria leonesa, en Patronos, promotores, mecenas y clientes. Actas del VII Congreso del CEHA, Murcia, Universidad de Murcia.

Sánchez Ameijeiras, Rocío (2000), Monumenta et memoria: the thirteenth century episcopal pantheon at Leon cathedral, en Valdez del Álamo, Elizabeth; Stamatis Pendergast, Carol (eds.), Memory and the Medieval Tomb, Aldershot, Ashgate, pp. 269-300.

Sánchez-Palencia Mancebo, Almudena (1988), Vida y empresas del arzobispo D. Pedro Tenorio, Toledo, Diputación provincial.

Sanz Sancho, Iluminado (2005), Notas sobre la casa de los obispos de Córdoba en la Edad Media, "Espacio, tiempo y forma. III. Historia medieval" 18, pp. 245-264.

Saraiva, Anísio Miguel de Sousa (2001-2002), O processo de inquiriçao do espólio de um prelado trecentista: D. Alfonso Pires, bispo do Porto (1359-1372†), "Lusitania Sacra" 13-14, pp. 197-228.

Serrano Coll, Marta; Boto Varela, Gerardo (2018), Memoria per corporis sensum combibit anima. Un relato histórico en la catedral de Tarragona: presencia y secuencia de ámbitos funerarios arzobispales, "Códex Aquilarensis" 34, pp. 115-142.

Teijeira Pablos, María Dolores (2014), De Sigüenza a Toledo. El patronazgo coral del cardenal Mendoza, en Teijeira Pablos, María Dolores; Herráez Ortega, María Victoria; Cosmen Alonso, María Concepción (eds.), Reyes y Prelados. La creación artística en los reinos de León y Castilla (1050-1500), Madrid, Sílex, pp. 403-416.

Teijeira Pablos, María Dolores (2018), The Last Service of a Prelate to his Cathedral. The Impact of Episcopal Wills on the Artistic Development of the Castilian Sees in Late Gothic Times, en Herráez Ortega, María Victoria; Cosmen Alonso, María Concepción; Teijeira Pablos, María Dolores; Moráis Morán, José Alberto (eds.), Obispos y catedrales. Arte en la Castilla bajomedieval, Berna, Peter Lang, pp. 259-288.

Teijeira Pablos, María Dolores (2019), The Altar of Santa Elena or Capilla de Pedro González de Mendoza in the cathedral of Toledo: the artistic work and its liturgical and spatial dimension, en Boto, Gerardo; Es- 
candell, Isabel; Lozano, Esther (eds.), The Memory of the Bishop in Medieval Cathedrals. Ceremonies and Visualizations, Berna, Peter Lang, pp. 299-346.

Teijeira Pablos, María Dolores; Herráez Ortega, María Victoria; Cosmen Alonso, María Concepción (2014), Reyes y Prelados. La creación artística en los reinos de León y Castilla (1050-1500), Madrid, Sílex.

Torres Fontes, Juan (1998), Cronología de los obispos de Cartagena en la Edad Media, "Anuario de Estudios Medievales" 28, pp. 661-677.

Valdés Fernández, Manuel; Cosmen Alonso, Concepción; Herráez Ortega, María Victoria; Campos Sánchez-Bordona, María Dolores; González-Varas Ibáñez, Ignacio (1994), Una historia arquitectónica de la catedral de León, León, Santiago García.

Valero Molina, Joan (2004), El sepulcre de Berenguer d'Anglesola i el seus referents en l'escultura funerària europea, "Annals de l'Institut d'Estudis Gironins" 45, pp. 687-732.

Vasallo Toranzo, Luis (2018), Los Fonseca. Linaje y patronato artístico, Valladolid, Universidad de Valladolid.

Villacampa Sanvicente, Susana (2018), El salón del Tanto Monta del palacio episcopal de Huesca: revisión de su origen y su evolución tras su reapertura, "Argensola" 127, pp. 15-48.

Villaseñor Sebastián, Fernando (2018), The Artistic Promotion of Lope de Barrientos, Bishop of Segovia, Ávila and Cuenca, en Herráez Ortega, María Victoria; Cosmen Alonso, María Concepción; Teijeira Pablos, María Dolores; Moráis Morán, José Alberto (eds.), Obispos y Catedrales. Arte en la Castilla bajomedieval, Berna, Peter Lang, pp. 183-220.

Yarza Luaces, Joaquín (1988), La capilla funeraria hispana en torno a 1400, en Núñez, Manuel; Portela, Ermelindo (coords.), La idea y el sentimiento de la muerte en la historia y en el arte de la Edad Media, Santiago de Compostela, Universidad de Santiago de Compostela, pp. 67-91.

Yarza Luaces, Joaquín (1992), Clientes, promotores y mecenas en el arte medieval hispano, en Patronos, promotores, mecenas y clientes. Actas del VII Congreso Nacional de Historia del Arte, Murcia, Universidad de Murcia.

Yarza Luaces, Joaquín; Herráez Ortega, María Victoria; Boto Varela, Gerardo (eds.) (2004), La Catedral de León en la Edad Media, León, Universidad de León.

Yuste Galán, Amalia; Passini, Jean (2011), El inicio de la construcción del claustro gótico de la catedral de Toledo, en Actas del VII Congreso Nacional de Historia de la Construcción, Madrid, Instituto Juan de Herrera, pp. 1477-1488.

Zaragoza Pascual, Ernesto (1995), Testamentaria inédita de don Alonso de Valdivieso, obispo de León (†1500), “Archivos Leoneses” 97-98, pp. 193-244. 